\title{
Étude expérimentale de l'évolution en microcosme du chrome (VI) dans l'eau de mer et de ses effets sur la macrofaune et les bactéries indigènes de la Lagune de Bizerte (Tunisie) Experimentation on chromium (VI): Evolution in sea water and impact on a clam and indigenous bacteria of Bizerte Lagoon
} (Tunisia)

\author{
Meriem Ben Khelil, Olfa Ben Said, Rachid Nefzi, Jamel Ben Abdelmalek et \\ Patricia Aïss
}

Volume 25, numéro 3, 2012

Reçu le 3 novembre 2011, accepté le 21 septembre 2012

URI : https://id.erudit.org/iderudit/1013104ar

DOI : https://doi.org/10.7202/1013104ar

\section{Aller au sommaire du numéro}

Éditeur(s)

Université du Québec - INRS-Eau, Terre et Environnement (INRS-ETE)

ISSN

1718-8598 (numérique)

Découvrir la revue

Citer cet article

Ben Khelil, M., Ben Said, O., Nefzi, R., Ben Abdelmalek, J. \& Aïss, P. (2012). Étude expérimentale de l'évolution en microcosme du chrome (VI) dans l'eau de mer et de ses effets sur la macrofaune et les bactéries indigènes de la Lagune de Bizerte (Tunisie). Revue des sciences de l'eau / Journal of Water Science, 25(3), 221-234. https://doi.org/10.7202/1013104ar
Résumé de l'article

La présente étude vise à comparer au laboratoire l'impact biologique du chrome hexavalent ( $\mathrm{Cr}$ (VI)) présent dans le ciment non déchromé, et celui du chrome présent dans le ciment déchromé en considérant deux échelons trophiques de la lagune de Bizerte : les bactéries indigènes et la macrofaune représentée par la palourde Ruditapes decussatus.

Dans deux types de microcosmes, l'un contenant de l'eau de mer seulement et l'autre contenant de l'eau de mer et du sédiment, la palourde européenne Ruditapes decussatus a été introduite à raison de 20 individus par aquarium. Quatre types d'aquarium ont été mis en place : un témoin (T), un aquarium contaminé par du ciment non déchromé $\left(0,16 \mathrm{mg} \cdot \mathrm{L}^{-1} \mathrm{de} \mathrm{Cr}(\mathrm{VI})\right)$, un contaminé par du ciment déchromé $\left(0,05 \mathrm{mg} \mathrm{L}^{-1} \mathrm{de} \mathrm{Cr}(\mathrm{VI})\right)$ et un contaminé par le dichromate de potassium $\left(0,16 \mathrm{mg}^{-1} \mathrm{~L}^{-1} \mathrm{de} \mathrm{Cr}(\mathrm{VI})\right)$. Deux replicats ont été réalisés pour chaque type de microcosme.

La concentration du Cr (VI) dans l'eau a été mesurée par un dosage colorimétrique au début et après 96 heures d'expérimentation. La quantification des bactéries hétérotrophes a été évaluée par la méthode du Nombre le Plus Probable.

Environ $80 \%$ de la quantité du $\mathrm{Cr}$ (VI) présente dans le milieu ont été piégés dans les sédiments. Les ciments déchromés et non déchromés ont provoqué $100 \%$ de mortalité chez les palourdes au bout de trois jours. Cependant, il n’a été observé que $40 \%$ de mortalité dans le microcosme contaminé par le $\mathrm{K}_{2} \mathrm{Cr}_{2} \mathrm{O}_{7}$. Une diminution de la charge bactérienne totale a été observée au niveau des sédiments pour tous les traitements.

On peut dire que la présence du sédiment a entraîné la diminution de la teneur du Cr (VI) dans l'eau et que malgré le déchromage du ciment, les deux types de ciment présentent un effet négatif sur les palourdes et les bactéries indigènes qui est plus marqué pour le ciment non déchromé. 


\title{
ÉTUDE EXPÉRIMENTALE DE L'ÉVOLUTION EN MICROCOSME DU CHROME (VI) DANS L'EAU DE MER ET DE SES EFFETS SUR LA MACROFAUNE ET LES BACTÉRIES INDIGÈNES DE LA LAGUNE DE BIZERTE (TUNISIE)
}

\author{
Experimentation on chromium (VI): Evolution in sea water and impact on a clam and indigenous bacteria of Bizerte Lagoon (Tunisia)
}

MERIEM BEN KHELIL ${ }^{a, b}$, OLFA BEN SAID ${ }^{a, *}$, RACHID NEFZI ${ }^{b}$, JAMEL BEN ABDELMALEK ET PATRICIA AÏSS $A^{a}$

${ }^{a}$ Laboratoire de Biosurveillance de l'Environnement (LBE), Faculté des Sciences de Bizerte, Zarzouna 7021, Bizerte, Tunisie.

${ }^{b}$ Laboratoire de contrôle qualité, Les Ciments de Bizerte Baie de Sabra, BP N53, 7018 Bizerte, Tunisie.

Reçu le 3 novembre 2011, accepté le 21 septembre 2012

\section{RÉSUMÉ}

La présente étude vise à comparer au laboratoire l'impact biologique du chrome hexavalent (Cr (VI)) présent dans le ciment non déchromé, et celui du chrome présent dans le ciment déchromé en considérant deux échelons trophiques de la lagune de Bizerte : les bactéries indigènes et la macrofaune représentée par la palourde Ruditapes decussatus.

Dans deux types de microcosmes, l'un contenant de l'eau de mer seulement et l'autre contenant de l'eau de mer et du sédiment, la palourde européenne Ruditapes decussatus a été introduite à raison de 20 individus par aquarium. Quatre types d'aquarium ont été mis en place : un témoin ( $T)$, un aquarium contaminé par du ciment non déchromé $\left(0,16 \mathrm{mg} \bullet \mathrm{L}^{-1}\right.$ de $\mathrm{Cr}(\mathrm{VI}))$, un contaminé par du ciment déchromé $\left(0,05 \mathrm{mg} \bullet \mathrm{L}^{-1}\right.$ de $\mathrm{Cr}(\mathrm{VI})$ ) et un contaminé par le dichromate de potassium $\left(0,16 \mathrm{mg} \bullet \mathrm{L}^{-1} \mathrm{de} \mathrm{Cr}(\mathrm{VI})\right)$. Deux replicats ont été réalisés pour chaque type de microcosme.

La concentration du Cr (VI) dans l'eau a été mesurée par un dosage colorimétrique au début et après 96 heures d'expérimentation. La quantification des bactéries hétérotrophes a été évaluée par la méthode du Nombre le Plus Probable.

Environ $80 \%$ de la quantité du Cr (VI) présente dans le milieu ont été piégés dans les sédiments. Les ciments déchromés et non déchromés ont provoqué $100 \%$ de mortalité chez les palourdes au bout de trois jours. Cependant, il n'a été observé que $40 \%$ de mortalité dans le microcosme contaminé par le $\mathrm{K}_{2} \mathrm{Cr}_{2} \mathrm{O}_{7}$. Une diminution de la charge bactérienne totale a été observée au niveau des sédiments pour tous les traitements.

On peut dire que la présence du sédiment a entraîné la diminution de la teneur du Cr (VI) dans l'eau et que malgré le déchromage du ciment, les deux types de ciment présentent un effet négatif sur les palourdes et les bactéries indigènes qui est plus marqué pour le ciment non déchromé.

Mots clés : Chrome hexavalent, macrofaune, bactéries indigènes, ciment déchromé, ciment non déchromé. 


\section{ABSTRACT}

This laboratory study aimed to compare the biological impact of hexavalent chromium (Cr (VI)) present in chromium-containing treated cement and in chromiumfree treated cement, by considering two trophic levels: the indigenous bacteria and macrofauna represented by the clam Ruditapes decussatus.

In both types of microcosms, one containing only seawater and the other containing seawater and sediment, European clams Ruditapes decussatus were introduced at a density of 20 individuals per aquarium. Four types of aquariums were used: control ( $\mathrm{T})$, contaminated with non-dechromated cement $\left(0.16 \mathrm{mg}^{\bullet} \mathrm{L}^{-1}\right.$ of $\left.\mathrm{Cr}(\mathrm{VI})\right)$, contaminated with dechromated cement $\left(0.05 \mathrm{mg} \cdot \mathrm{L}^{-1}\right.$ of $\left.\mathrm{Cr}(\mathrm{VI})\right)$, and one contaminated with potassium dichromate $\left(0.16 \mathrm{mg}^{\bullet} \mathrm{L}^{-1}\right.$ of $\left.\mathrm{Cr}(\mathrm{VI})\right)$. Two replicates were performed for each type of microcosm. The Cr (VI) content of the water was determined with a colorimetric assay at the beginning of the experiment and after $96 \mathrm{~h}$. The quantification of heterotrophic bacteria was performed by the Most Probable Number method.

About $80 \%$ of the Cr (VI) present in the sedimentwater aquarium was trapped in the sediment. Cement, nondechromated and dechromated, caused $100 \%$ clam mortality after three days. However, only $40 \%$ clam mortality was observed in aquariums contaminated with $\mathrm{K}_{2} \mathrm{Cr}_{2} \mathrm{O}_{7}$. A decrease in total bacterial load was observed in the sediment for all treatments.

We conclude that the presence of sediment in the aquariums led to a reduction of the $\mathrm{Cr}$ (VI) concentration in the overlying water, and that despite the chromium removal treatment effected on one of the cements, both types of cement had a negative impact on clams and indigenous bacteria, the impact being stronger for chromium-containing treated cement.

Keywords: Hexavalent chromium, macrofauna, indigenous bacteria, dechromated cement, non-dechromated cement.

\section{INTRODUCTION}

Le développement industriel et l'urbanisation sont en croissance presque exponentielle dans le nord-est de la Tunisie (BARRO, 2010). Cette dernière a permis des progrès considérables pour l'humanité mais a aussi engendré de nombreuses conséquences néfastes pour l'environnement et pour l'Homme (BARRO, 2010). Certains problèmes environnementaux relèvent notamment de l'industrie cimentière, étroitement liée à l'activité du secteur de la construction. Le ciment est essentiellement un mélange obtenu après cuisson de $80 \%$ de calcaire et de $20 \%$ d'argile (GUILLON, 2004). Sous l'effet de la chaleur, ses constituants, principalement des composés de silicate d'aluminium et d'oxyde de fer, se combinent à la chaux provenant du calcaire pour donner des silicates et des aluminates de calcium (Silicate tricalcique $\left(\mathrm{C}_{3} \mathrm{~S}\right)$ de $50 \%$ à $70 \%$; Silicate dicalcique $\left(\mathrm{C}_{2} \mathrm{~S}\right)$ de $15 \%$ à $30 \%$; Aluminate tricalcique $\left(\mathrm{C}_{3} \mathrm{~A}\right)$ de $5 \%$ à $15 \%$ et Aluminoferritetétracalcique $\left(\mathrm{C}_{4} \mathrm{AF}\right)$ de $5 \%$ à $\left.15 \%\right)$ (GUILLON, 2004). En outre, le ciment contient divers composés métalliques (Mercure, Baryum, Chrome, Arsenic, Nickel, Cuivre, Argent, Cadmium, Plomb, Sélénium, Zinc, Potassium, etc. (COMMISSION EUROPÉENNE, 2010).

Le chrome qui figure parmi les métaux les plus toxiques engendre des réactions allergiques par contacts prolongés et répétés avec la peau, après adjonction d'eau (OPPBTP, 1990). Le chrome hexavalent, la forme la plus problématique, est très toxique et très soluble dans l'eau (MAKDISI, 1992). Cette solubilité lui confere une grande mobilité dans les écosystèmes si bien qu'une pollution au chrome (VI), d'abord très localisée, peut ensuite intéresser une zone beaucoup plus vaste (AFRI-MEHENNAOUI et al., 2009). Le chrome hexavalent, présent dans le ciment à faible concentration, est un allergène très puissant qui déclenche l'apparition d'eczémas, d'asthme et de rhinites (INERIS, 2005), et de plus il peut, dans l'eau, être mutagène et cancérigène. La directive européenne 2003/53/CE a exigé que le ciment commercialisé sur le marché européen ait des teneurs en Chrome (VI) inférieures à $2 \mathrm{ppm}$ $(0,0002 \%)$ (COMMISSION EUROPÉENNE, 2003). En milieu aquatique, les organismes inférieurs sont plus sensibles que les poissons. De plus, le chrome hexavalent, toxique pour la faune aquatique d'eau douce à une concentration relativement élevée (inhibition de croissance du phytoplancton d'eau douce vers $\left.10 \mu \mathrm{g}^{\bullet} \mathrm{L}^{-1}\right)$, est peu toxique dans l'eau salée (CHIFFOLEAU, 2001). Si certaines études comme celles de GUILLON (2004), LOOTENS (2004) et MOUDILOU (2000) se sont intéressé aux caractéristiques physicochimiques et mécaniques du ciment, d'autres comme celles de DESJARDIN (2002), JOUANY et al. (1982), etc. ont évalué l'impact du chrome (VI), seul, sur l'environnement. Cependant, aucune d'entre elles n'a déterminé l'impact du chrome (VI) présent dans le ciment sur l'environnement. L’objectif de la présente étude est de comparer au laboratoire l'impact biologique des substances contenues (globalement) dans deux ciments différents : le ciment non déchromé et le ciment déchromé, plus ou moins dilués, jusqu’à obtention de suspensions contenant en solution des concentrations de chrome (VI) de $0,16 \mathrm{mg} \bullet \mathrm{L}^{-1}$ pour le ciment non déchromé et de $0,05 \mathrm{mg} \cdot \mathrm{L}^{-1}$ pour le ciment déchromé, en considérant deux échelons trophiques de la lagune de Bizerte : les bactéries indigènes et la macrofaune. 


\section{MATÉRIEL ET MÉTHODES}

\subsection{Présentation de l'espèce}

L'espèce macrobenthique retenue est la palourde européenne Ruditapes decussatus. Cet excellent bioindicateur de la pollution marine (CHOUBA et al., 2008) a déjà été utilisé avec la moule pour évaluer l'état de contamination du littoral tunisien et notamment celui de la lagune de Bizerte (DELLALI et al., 2001).

\section{2 Échantillonnage}

Trois stations d'échantillonnage localisées près du rivage ont été choisies. La collecte de l'espèce macrobenthique Ruditapes decussatus et le prélèvement du sédiment ont été réalisés dans la lagune de Bizerte (nord-est de la Tunisie); exactement au niveau de la station Faroua, une station relativement propre (DELLALI et al., 2001) située à l'Ouest (Figure 1), pour le premier et au niveau de la station Echaâra, une station chimiquement propre (BEN SAID et al., 2010a) localisée au Nord-Ouest, pour le second. Cependant, le prélèvement des échantillons d'eau de mer a été réalisé au niveau de la Méditerranée à la station La Grotte, loin de toute contamination industrielle (Figure 1).

La collecte d'échantillons d'eaux et de sédiments a été réalisée d'une façon stérile (OMS, 1995). Les sédiments ont été extraits à l'aide de carottiers en plexiglas de $10 \mathrm{~cm}$ de section (LOUATI et al., 2012) introduits à une profondeur de $10 \mathrm{~cm}$, tamisés sur place sur un tamis de $63 \mu \mathrm{m}$ pour enlever les grosses particules puis transférés dans des boîtes préalablement stérilisées. Alors que pour l'eau, le prélèvement a été réalisé par plongées autonomes dans des bidons stériles. Dès le retour au laboratoire, le sédiment a été manuellement homogénéisé avec une large spatule et réparti dans des boîtes stériles et conservé à $4^{\circ} \mathrm{C}$ avant d'être utilisé pour le remplissage des différents microcosmes. Les échantillons d'eaux ont été filtrés à $0,20 \mu \mathrm{m}$ puis stérilisés pendant 20 min à $121^{\circ} \mathrm{C}$ et 1 bar puis conservés aussi à $4^{\circ} \mathrm{C}$.

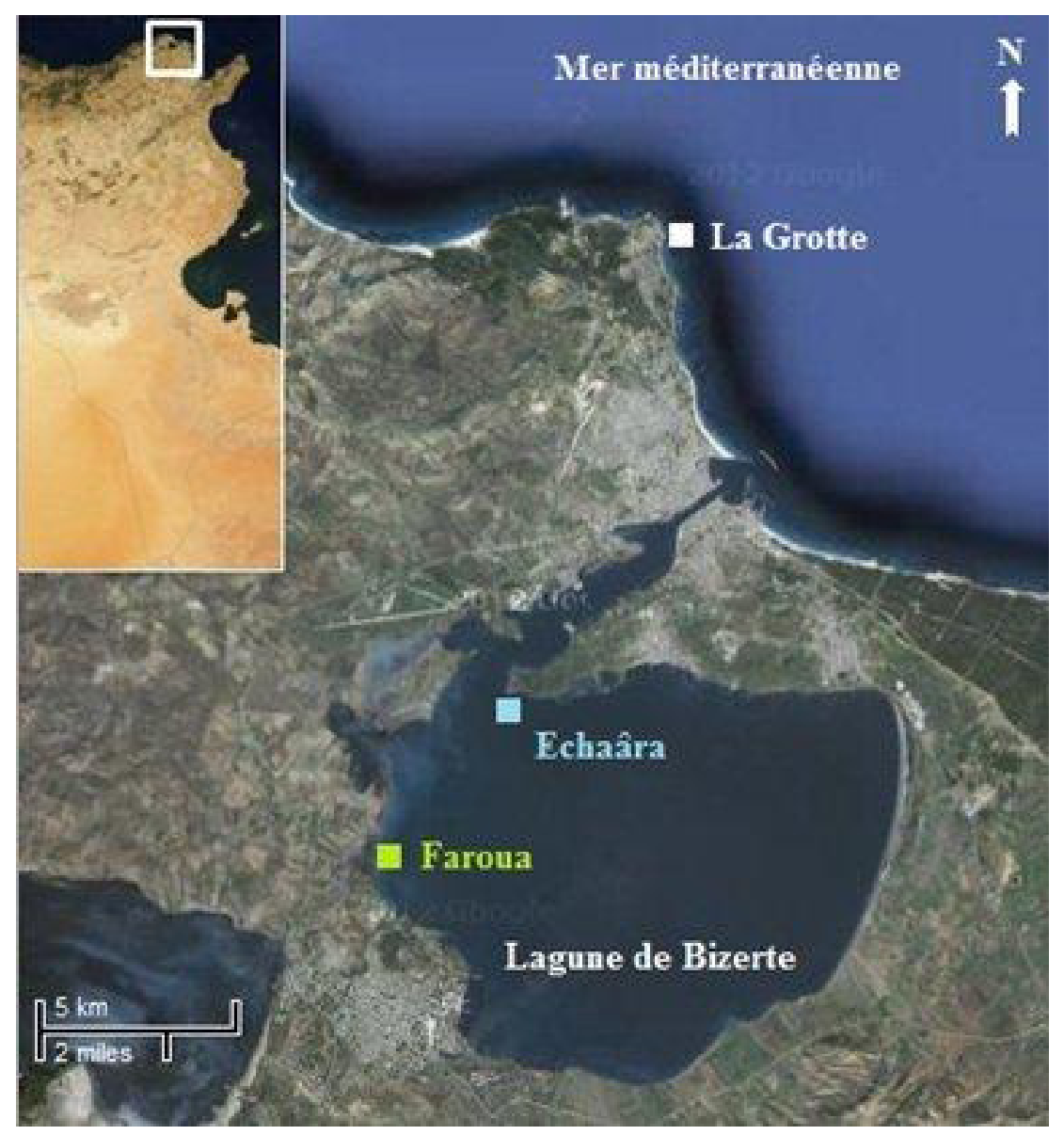

Figure 1. Localisation des stations d'échantillonnage dans la lagune de Bizerte et au niveau de la Méditerranée à proximité de la ville de Bizerte (près du rivage). Location of sampling stations in the Bizerte lagoon and in the Mediterranean Sea near the town of Bizerte (not far from the shore). 


\subsection{Installation des microcosmes " aquariums "}

Pour atteindre les objectifs de cette étude, on a mis en place deux types de microcosmes, l'un contenant seulement de l'eau de mer et l'autre contenant de l'eau de mer et du sédiment. L'utilisation de ces deux types de microcosmes doit permettre de suivre le devenir du chrome et de mettre en évidence le rôle réducteur du sédiment (FENDORF, 1995).

\subsubsection{Définition d'un microcosme}

Un microcosme est un système artificiel clos de laboratoire, constitué des composantes abiotiques de l'écosystème simulé et de plusieurs espèces représentatives de différents niveaux trophiques, le plus souvent sous conditions environnementales contrôlées (TRIFFAULT-BOUCHET et MARTEL, 2005).

\subsubsection{Microcosmes utilisés}

Dans des microcosmes couverts $\left[\begin{array}{lllll}30 & \mathrm{~cm} & \mathrm{x} & 40 & \mathrm{~cm}\end{array}\right]$ préalablement stérilisés, contenant un volume final de 6 litres d'eau de mer filtrée $(0,2 \mu \mathrm{m})$ et stérilisée, avec ou sans ajout de sédiment (3 L/1 kg), l'espèce Ruditapes decussatus a été introduite à raison de 20 palourdes $(3,5 \pm 0,4 \mathrm{~cm})$ par microcosme.

Pour chaque type de microcosme (contenant seulement de l'eau de mer et contenant de l'eau de mer et du sédiment) quatre types d'aquariums ont été mis en place : le premier est un témoin (T) sans aucun polluant ajouté, le second est contaminé par du ciment non déchromé $\left(0,16 \mathrm{mg}^{\bullet} \mathrm{L}^{-1}\right.$ de $\left.\mathrm{Cr}(\mathrm{VI})\right)$, le troisième est contaminé par du ciment déchromé $\left(0,05 \mathrm{mg}^{\bullet} \mathrm{L}^{-1}\right.$ de $\mathrm{Cr}(\mathrm{VI})$ ) et le quatrième est contaminé seulement par du dichromate de potassium, $\mathrm{K}_{2} \mathrm{Cr}_{2} \mathrm{O}_{7}$, servant de témoin positif de la contamination par le chrome $\left(0,16 \mathrm{mg}^{\bullet} \mathrm{L}^{-1}\right.$ de $\left.\mathrm{Cr}(\mathrm{VI})\right)$
(Tableau 1). Deux replicats ont été considérés pour chaque type de microcosme (Figure 2).

\subsection{Contamination de la colonne d'eau}

\subsubsection{Types 1 et 2 : contamination par le ciment (déchromé ou non déchromé)}

Les concentrations en chrome (VI) des deux types de ciment étudiées dans la présente étude étaient imposées par la quantité de ciment soluble dans le volume d'eau de mer utilisé pour la préparation de la solution mère (NF EN 196-10, 2009) : Pour chaque type de ciment (déchromé et non déchromé) un mélange ciment/eau $(2 / 3 / 1 / 3)$ préalablement homogénéisé avec un malaxeur à deux vitesses (NF EN 196-10, 2009), a été filtré sous vide, le filtrat obtenu constitue la solution mère. Cette solution a été utilisée pour la contamination de la colonne d'eau de mer des aquariums à raison de $1 / 5 \mathrm{~V} / \mathrm{V}$. Après homogénéisation du volume total (6 litres), un volume de $5 \mathrm{~mL}$ a été prélevé pour déterminer la concentration en chrome (VI) dans chaque aquarium (NF EN 196-10, 2009).

\subsubsection{Type 3 : contamination avec le dichromate de potassium}

Une solution de $0,16 \mathrm{mg}^{\bullet} \mathrm{L}^{-1}$ de $\mathrm{Cr}(\mathrm{VI})$ a été préparée à partir du dichromate de potassium en poudre. Ce test est considéré comme un témoin positif de la contamination par le chrome hexavalent.

L'expérimentation a été réalisée à température ambiante et en utilisant la lumière du jour. Au démarrage de la manipulation, une goutte de phytoplancton (Liquizelle),

Tableau 1. Tests et types de microcosmes utilisés.

Table 1. Tests and types of microcosms.

\begin{tabular}{llccc}
\hline \multirow{2}{*}{ Code } & Identification & \multicolumn{2}{c}{ Types de microcosmes } & $\begin{array}{c}\text { Teneur en } \mathrm{Cr}(\mathrm{VI}) \\
\text { en } \mathrm{mg}^{-1} \mathrm{~L}^{-1}\end{array}$ \\
\cline { 3 - 4 } $\mathrm{T}$ & Témoin & Eau propre & $\begin{array}{l}\text { Eau propre et sédiment } \\
\text { naturel }\end{array}$ & - \\
$\mathrm{Cnd}$ & Contaminé & Contaminé par le ciment non déchromé & 0,16 \\
$\mathrm{~K}_{2} \mathrm{Cr}_{2} \mathrm{O}_{7}$ & Témoin positif & Contaminé par le dichromate de potassium & 0,16 \\
$\mathrm{Cd}$ & Contaminé & Contaminé par le ciment déchromé & 0,05 \\
\hline
\end{tabular}


A
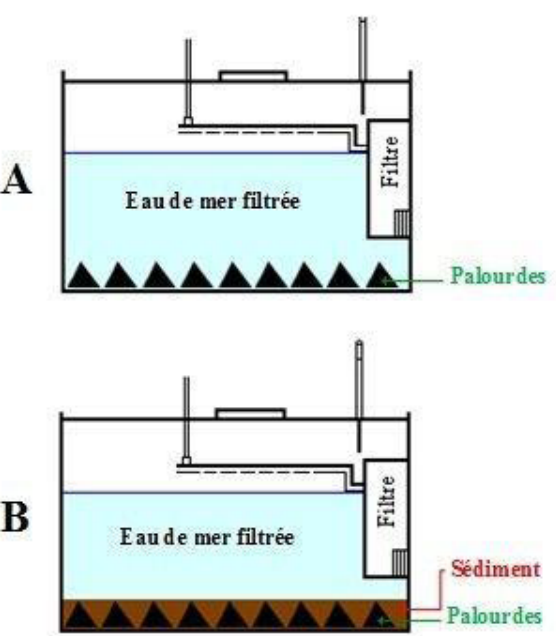

Aquarium témoin
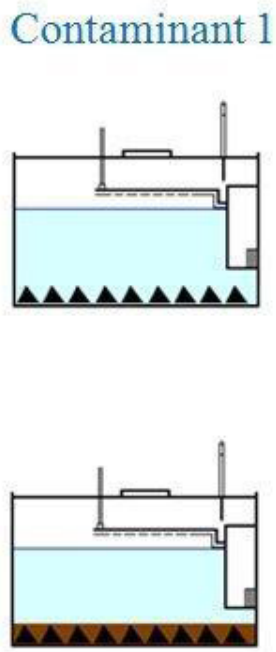

Ciment déch romé $\left(0,05 \mathrm{mg}^{-1} \mathrm{de} \operatorname{Cr}\right.$ (VI))
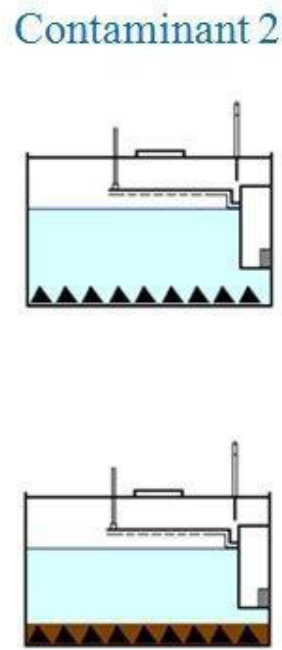

Ciment non déchromé (0,16 $\left.\mathrm{mg} \mathrm{L}^{-1} \mathrm{de} \mathrm{Cr}(\mathrm{VI})\right)$
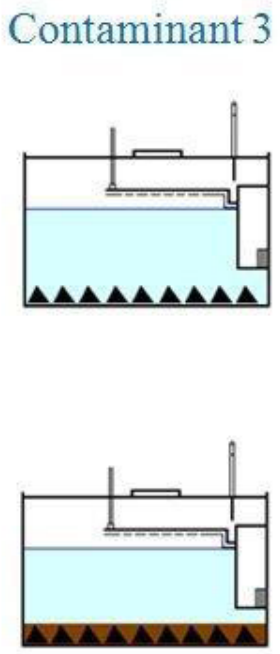

Dichromate de potassium $\left(0,16 \mathrm{mg}^{-1} \mathrm{Le}^{-\mathrm{Cr}}\right.$ (VI))

Figure 2. Schémas des deux types de microcosmes étudiés. A : Microcosmes « $\mathrm{E}$ » contenant seulement de l'eau de mer; $\mathrm{B}: \mathrm{Microcosmes} \mathrm{«} \mathrm{ES}$ » contenant de l'eau de mer et du sédiment.

Diagrams of two types of studied microcosms. A: Microcosms «E» containing only seawater; B: Microcosms «ES» containing seawater and sediment.

servant comme nourriture pour les palourdes, a été ajoutée dans chaque aquarium.

\subsection{Dosage du Chrome (VI) dans l'eau}

Les teneurs en chrome (VI) des solutions ont été déterminées par un dosage colorimétrique grâce à un spectrophotomètre (Jenway 6300) en utilisant le diphénylcarbohydrazide à $540 \mathrm{~nm}$ de longueur d'onde (NF EN 196-10, 2009). La limite de détection de cette méthode était de $0,10 \mathrm{mg}^{\bullet} \mathrm{L}^{-1}(\mathrm{CEAEQ}$, 2008).

\subsection{Détermination du pourcentage de mortalité chez les palourdes}

Un suivi journalier (trois jours seulement à cause de l'obtention de $100 \%$ de mortalité dans quelques aquariums) de la mortalité a été réalisé; les individus morts ont été éliminés au fur et à mesure.

\subsection{Quantification des bactéries indigènes totales}

La quantification des bactéries indigènes totales dans le sédiment a été faite par la méthode NPP (Nombre le Plus
Probable) à trois tubes (HEIKE et al., 2009). De chaque microcosme, $1 \mathrm{~g}$ de sédiment a été prélevé en utilisant du matériel stérilisé et dans des conditions stériles (en présence de flamme), puis dilué et mis en suspension dans $9 \mathrm{~mL}$ d'eau physiologique $(0,9 \%$ de chlorure de sodium) stérile. Après homogénéisation au vortex, des dilutions décimales successives ont été préparées. $1 \mathrm{~mL}$ de chacune des dilutions $10^{-2}, 10^{-3}$ et $10^{-4}$ a été inoculé dans $9 \mathrm{~mL}$ d'un milieu de culture déshydraté utilisé pour la culture des bactéries hétérotrophes marines " Marine 2216 - Bouillon " préalablement stérilisé et réparti dans trois tubes à essai pour chaque dilution. Après $48 \mathrm{~h}$ d'incubation à $30^{\circ} \mathrm{C}$, la charge bactérienne a été déterminée selon la table de Mac Grady (CUQ, 2008).

\subsection{Analyses statistiques}

Les comparaisons entre moyennes ont été réalisées avec le logiciel Statistica 8.0. L'homogénéité des variances a été testée à l'aide du test "Cochran C, Hartley, Bartlett". La comparaison des moyennes a été effectuée avec l'Anova à un seul facteur et l'Anova à deux facteurs. Une fois qu'une différence significative a été détectée avec l'Anova, un test Post-hoc "Tukey HSD" a été appliqué. La différence significative a été considérée à $\mathrm{p}<0,05$. 


\section{RÉSULTATS ET DISCUSSIONS}

\subsection{Devenir du chrome hexavalent présent dans les deux types de ciment : ciment déchromé et ciment non déchromé et son impact sur Ruditapes decussatus}

On observe sur la figure 3 que la teneur en Cr (VI) dans les microcosmes de type $\mathrm{E}$ contenant seulement de l'eau de mer varie peu en fonction du temps : La teneur en Cr (VI) a diminué d'environ $18 \%$ dans les aquariums contaminés par le ciment déchromé et d'environ $6 \%$ dans les aquariums contaminés par le ciment non déchromé. L'utilisation du test Anova à deux facteurs : type de contamination (T, Cnd, Cd; $\mathrm{ddl}=2)$ et temps d'expérimentation $(0 \mathrm{~h}, 96 \mathrm{~h} ; \mathrm{ddl}=1)$ ne montre pas une différence temporelle significative de la teneur en $\mathrm{Cr}$ (VI) dans l'eau pour un même type de contamination $(\mathrm{ddl}=2 ; \mathrm{F}=0,717 ; \mathrm{p}=0,525)$.

Par contre, la teneur en Cr (VI) a diminué considérablement, au cours de l'expérimentation, dans les microcosmes de type ES contenant l'eau de mer plus du sédiment; elle a diminué d'environ $66 \%$ dans les aquariums contaminés par le ciment déchromé et d'environ $90 \%$ dans les aquariums contaminés par le ciment non déchromé. L'utilisation du test Anova à deux facteurs : type de contamination $(\mathrm{T}, \mathrm{Cnd}, \mathrm{Cd}$; $\mathrm{ddl}=2$ ) et temps d'expérimentation $(0 \mathrm{~h}, 96 \mathrm{~h} ; \mathrm{ddl}=1)$, montre une diminution temporelle hautement significative de la teneur en $\mathrm{Cr}$ (VI) dans l'eau pour un même type de contamination $(\mathrm{ddl}=2 ; \mathrm{F}=451,958 ; \mathrm{p}<0,001)$.

D'après la figure 4, la mortalité des palourdes dans les microcosmes ES a atteint $100 \%$, après seulement $72 \mathrm{~h}$ d'expérimentation, dans les deux types d'aquariums contaminés par le ciment. Par contre, dans les microcosmes E contenant seulement de l'eau, elle est de $40 \%$ dans les aquariums contaminés par le ciment non déchromés et de $5 \%$ seulement dans les aquariums contaminés par le ciment déchromés. Les résultats du test statistique Anova à deux facteurs : type de contamination ( $\mathrm{T}, \mathrm{Cnd}, \mathrm{Cd}$; $\mathrm{ddl}=2$ ) et types de microcosmes $\mathrm{E}$ et $\mathrm{ES}(\mathrm{ddl}=1)$ montrent une différence hautement significative

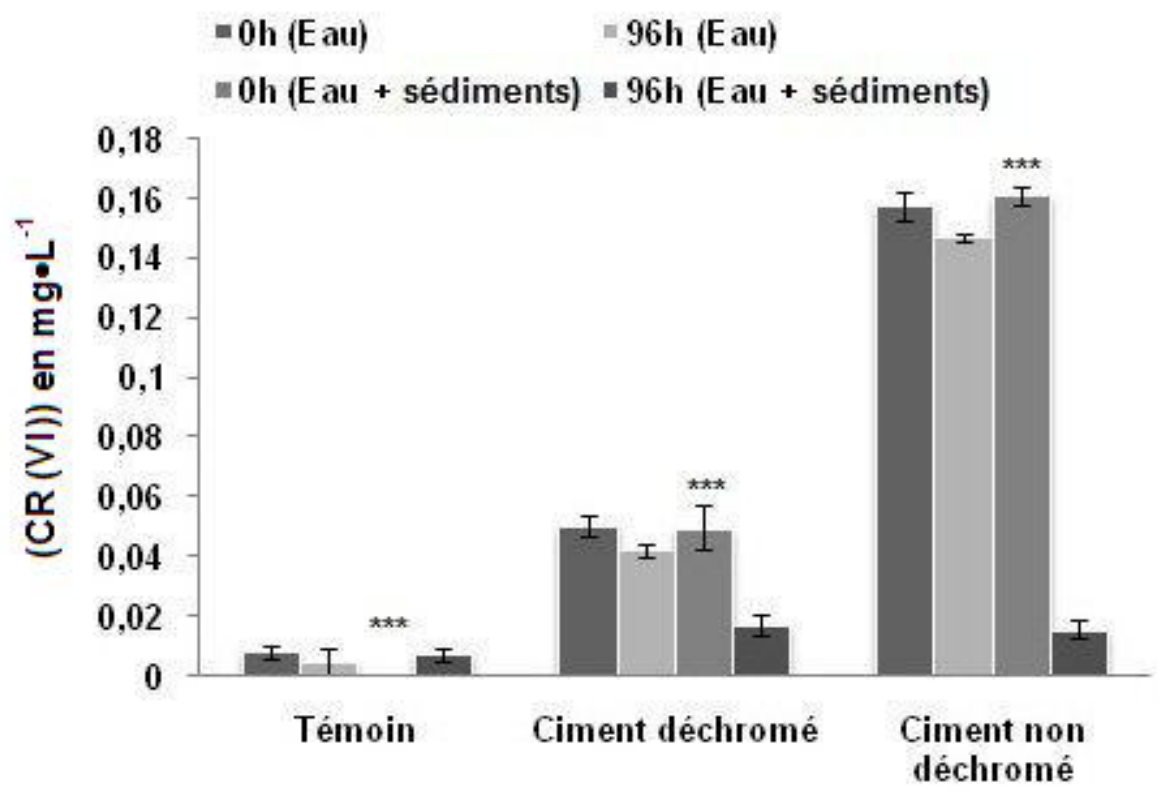

Figure 3. Variation temporelle de la teneur en Cr (VI), libéré par les deux types de ciment, dans la colonne d'eau de deux types de microcosmes différents « $E$ » (contenant seulement de l'eau de mer) et «ES " (contenant aussi du sédiment) (Moyenne \pm Écarts-types) au début de l'expérience puis après $96 \mathrm{~h}$.

Temporal variation in the content of $\mathrm{Cr}(V I)$, released by both types of cement in the water column of two different types of microcosms "E» (containing only seawater) and «ES» (also containing sediment) (Mean $\pm S D)$ at the beginning and after $96 \mathrm{~h}$. 


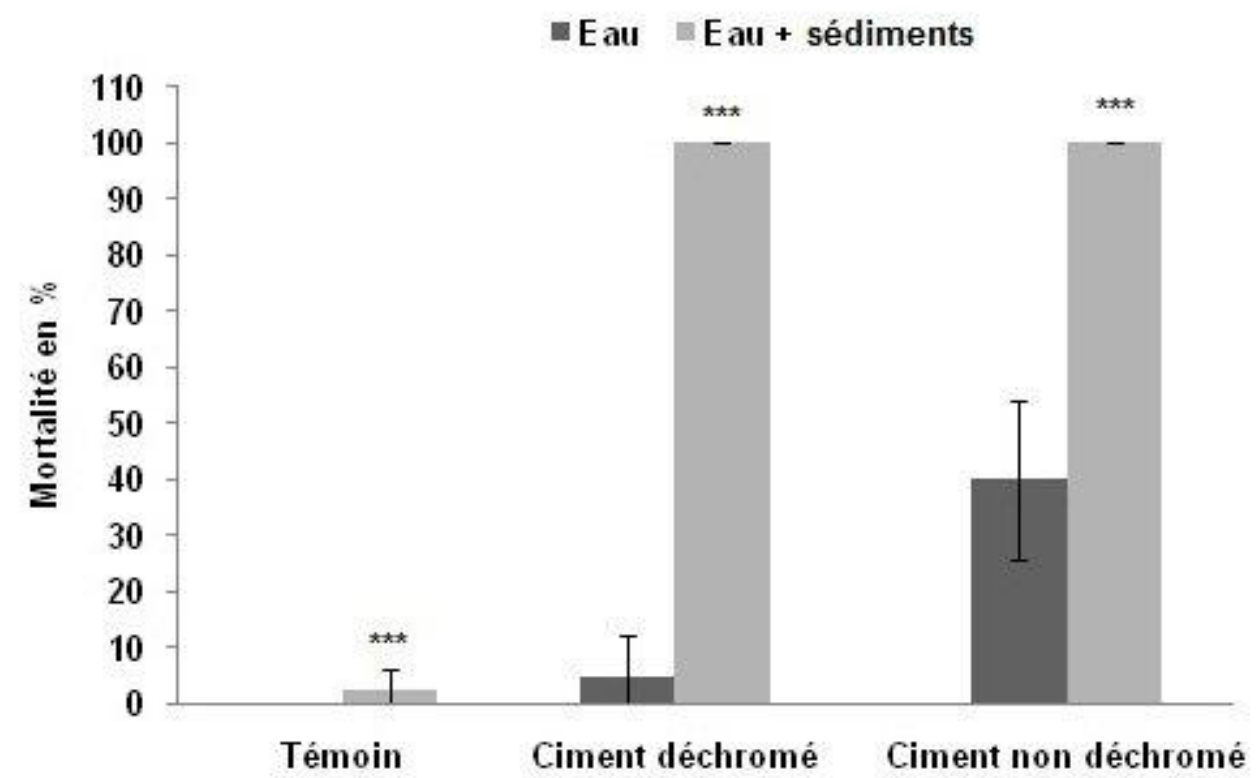

Figure 4. Comparaison de la mortalité des palourdes après $72 \mathrm{~h}$ d'expérimentation dans les deux types de microcosmes « E » et « ES " (Moyenne \pm Écarts-types). Comparison of clam mortalities after $72 \mathrm{~b}$ of experimentation in both types of microcosms «E» and «ES» (mean $\pm S D)$.

de la mortalité en fonction de ces deux paramètres $(\mathrm{ddl}=2$; $\mathrm{F}=49,857 ; \mathrm{p}<0,001)$.

Au cours des expérimentations, on a observé une diminution considérable de la teneur de l'eau en chrome (VI) dans les microcosmes ES, par comparaison avec la teneur en chrome des microcosmes $\mathrm{E}$ sans sédiment. Cette diminution importante de la teneur en $\mathrm{Cr}$ (VI) peut être due à la sédimentation du métal, ou à une adsorption des ions $\mathrm{Cr}$ (VI) sur des particules du sédiment, puis à la réduction de ce dernier en Cr (III) (DESJARDIN, 2002). Cette réduction peut avoir lieu en présence de fer ferreux (Fe (II)), et de matières organiques (DESJARDIN, 2002). En effet, le fer (II) semble être le plus important des réducteurs possibles du $\mathrm{Cr}$ (VI) dans l'environnement (DESJARDIN, 2002).

Les études menées sur la réduction du Cr (VI) par le Fe (II) en solution ont montré que, outre les concentrations respectives des deux espèces ( $\mathrm{Cr}(\mathrm{VI})$ et $\mathrm{Fe}(\mathrm{II})$ ), le $\mathrm{pH}$ et la température influençaient la vitesse de réaction. Les $\mathrm{pH}$ pour lesquels on observe des cinétiques de réaction les plus rapides sont proches de la neutralité, compris entre 6 et 8 selon BUERGE et HUG (1997) et SEDLAK et CHAN (1997). L'élévation de la température permet, aussi, d'augmenter la vitesse de réaction (PETTINE et al. (1998), SEDLAK et CHAN (1997)).

Les matières organiques naturelles (acides humiques ou fulviques) contenues dans les sols sont également susceptibles de réduire le chrome (VI) (ALLOWAY (1995), BARTLETT et KIMBLE (1976), JAMES et BARTLETT (1983)). Grâce à leur pouvoir chélateur et leur propriété d'oxydoréduction, les matières humiques du sol ou d'un sédiment constituent en effet un système actif d'oxydoréduction donc, le cas échéant, d'épuration vis-à-vis du chrome (VI).

Les acides fulviques sont de meilleurs réducteurs que les acides humiques parce qu'ils sont moins sensibles à l'inhibition par le Cr (III) (PALMER et WITTBRODT, 1991). Il semble que la vitesse de réduction du $\mathrm{Cr}(\mathrm{VI})$ par les acides fulviques et humiques soit modifiée par la présence de Fe (III). En fait, en présence de $\mathrm{Fe}$ (III), deux phénomènes pourraient se produire : le premier serait la réduction plus rapide du Fe (III) en Fe (II) par les acides humiques. Puis le $\mathrm{Fe}$ (II) ainsi formé qui réduirait le $\mathrm{Cr}$ (VI). Le second phénomène, toujours selon PALMER et WITTBRODT (1991), serait la formation du complexe $\mathrm{FeCrO}_{4}^{+}$qui, notamment à la surface des substances humiques, permettrait la réduction du chrome (VI).

Malgré la diminution de la teneur en Cr (VI) dans la colonne d'eau, dans les microcosmes eau-sédiment, la mortalité des individus a été maximale $(100 \%)$ au bout de $72 \mathrm{~h}$. Ceci pourrait s'expliquer par la bioaccumulation, par voie directe (bioconcentration), du métal dans les tissus du mollusque suite à une désorption des éléments métalliques fixés sur les particules inertes ou vivantes en suspension dans l'eau et qui, 
filtrées par les palourdes, leur servent de nourriture (AMIARD et al., 1991).

\subsection{Devenir du chrome hexavalent présent dans deux types de ciment et dans le dichromate de potassium et impact de ce chrome sur le Bivalve Ruditapes decussatus}

La figure 5 montre une diminution considérable de la teneur en $\mathrm{Cr}$ (VI) en fonction du temps dans les microcosmes ES contenant de l'eau et du sédiment; elle est d'environ $66 \%$ dans les aquariums contaminés par le ciment déchromé, d'environ $95 \%$ dans les aquariums contaminés par $\mathrm{K}_{2} \mathrm{Cr}_{2} \mathrm{O}_{7}$ et d'environ $90 \%$ dans les aquariums contaminés par le ciment non déchromé. L'utilisation du test Anova à deux facteurs : type de contamination ( $\mathrm{T}$, Cnd, $\mathrm{K}_{2} \mathrm{Cr}_{2} \mathrm{O}_{7}, \mathrm{Cd}$; ddl = 3) et temps ( $0 \mathrm{~h}$, $96 \mathrm{~h}$; ddl =1) montre une diminution temporelle hautement significative de la teneur en $\mathrm{Cr}(\mathrm{VI})$ dans l'eau pour un même type de contamination $(\mathrm{ddl}=3 ; \mathrm{F}=560,996 ; \mathrm{p}<0,001)$.

$\mathrm{Au}$ contraire, la teneur en chrome varie peu dans les microcosmes contenant seulement de l'eau de mer; elle est d'environ $18 \%$ dans les aquariums contaminés par le ciment déchromé, d'environ $3 \%$ dans les aquariums contaminés par $\mathrm{K}_{2} \mathrm{Cr}_{2} \mathrm{O}_{7}$ et d'environ $6 \%$ dans les aquariums contenant le ciment non déchromé. L'utilisation du test Anova à deux facteurs : type de contamination ( $\mathrm{T}, \mathrm{Cnd}, \mathrm{K}_{2} \mathrm{Cr}_{2} \mathrm{O}_{7}, \mathrm{Cd}$; $\mathrm{ddl}=3)$ et temps $(0 \mathrm{~h}, 96 \mathrm{~h} ; \mathrm{ddl}=1)$ ne montre pas une variation temporelle significative pour un même type de contamination $(\mathrm{ddl}=3 ; \mathrm{F}=0,793 ; \mathrm{p}=0,531)$.

Dans les microcosmes ES, le pourcentage de mortalité est de $15 \%$, après $72 \mathrm{~h}$ d'expérimentation, dans les aquariums contaminés par $\mathrm{K}_{2} \mathrm{Cr}_{2} \mathrm{O}_{7}$ et atteint $100 \%$ dans les aquariums contaminés par les deux types de ciment (Figure 6). Dans les microcosmes E, elle est seulement de $5 \%$ dans les aquariums contaminés par le dichromate et dans ceux contaminés par le ciment déchromé et de $40 \%$ dans les aquariums contaminés par le ciment non déchromé.

On note aussi que le pourcentage de mortalité dans les microcosmes ES est significativement plus élevé que celui qui s'observe dans les microcosmes E (Figure 6). Les résultats du test statistique Anova à deux facteurs : type de contamination ( $\mathrm{T}$, Cnd, $\mathrm{K}_{2} \mathrm{Cr}_{2} \mathrm{O}_{7}, \mathrm{Cd}$; ddl = 3) et types de microcosmes $\mathrm{E}$ et ES ( $\mathrm{ddl}=1)$ montrent une différence hautement significative de la mortalité en fonction de ces deux paramètres $(\mathrm{ddl}=3 ; \mathrm{F}=42,057 ; \mathrm{p}<0,001)$.

Le taux de mortalité dans les microcosmes contaminés par le ciment a toujours été au moins égal (dans les aquariums E avec le ciment "déchromé »), ou très supérieur (dans les aquariums ES, quel que soit le ciment utilisé), au taux de mortalité observé dans les microcosmes contaminés uniquement

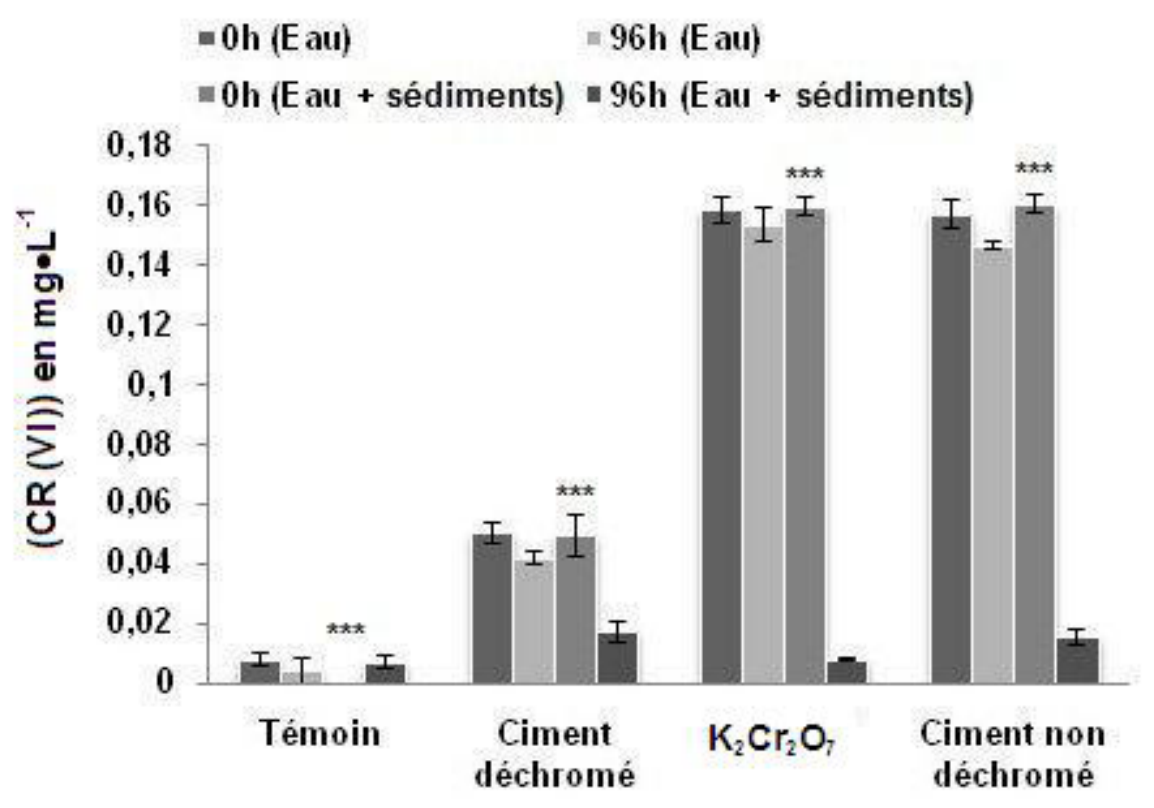

Figure 5. Variation temporelle de la teneur en $\mathrm{Cr}$ (VI) dans la colonne d'eau de deux types de microcosmes différents (Eau et Eau + sédiments) pour trois types de contaminations (ciment non déchromé, ciment déchromé et le dichromate de potassium) (Moyenne \pm Écarts-types).

Temporal variation in the $\mathrm{Cr}(V I)$ content of the water column of two different types of microcosms (water and water + sediment) for three types of contamination (non-dechromated cement, dechromated cement and potassium dichromate) (mean $\pm D)$. 


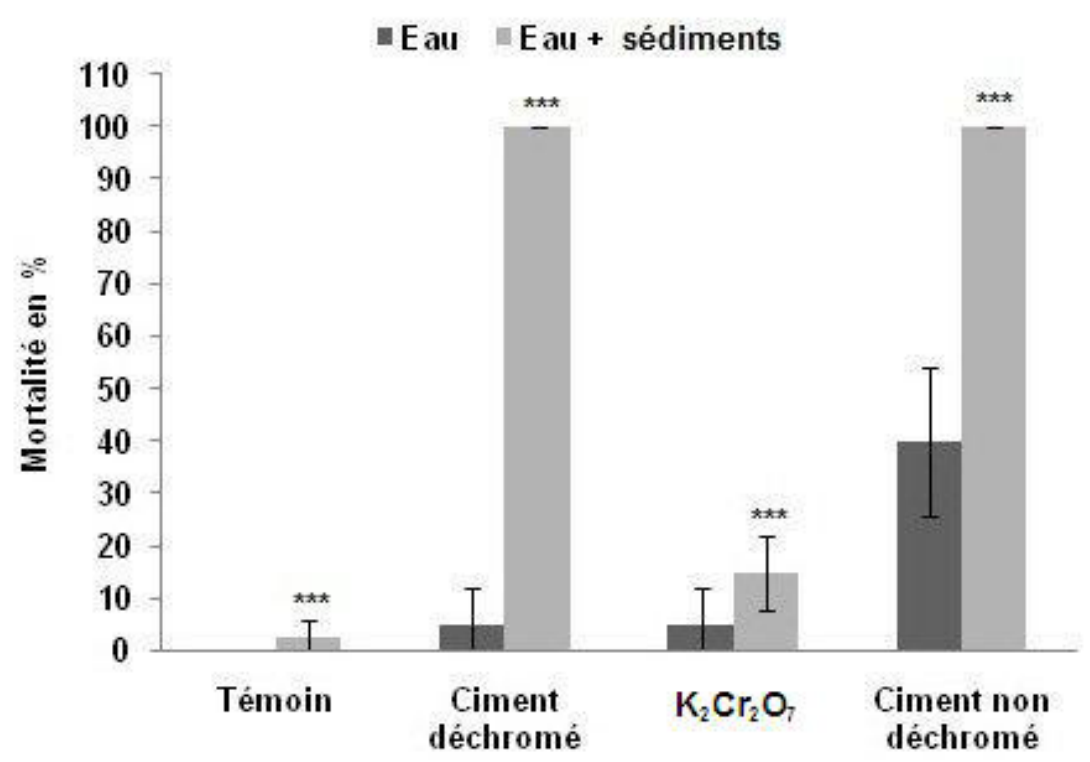

Figure 6. Comparaison de la mortalité des palourdes après $72 \mathrm{~h}$ d'expérience pour trois types de contamination dans deux types de microcosmes différents (Moyenne \pm Écarts-types).

Comparison of clam mortalities after $72 \mathrm{~h}$ for three types of contamination in two different types of microcosms (mean $\pm S D$ ).

par le dichromate de potassium. La figure 7 montre une très faible mortalité des palourdes dans les aquariums contaminés par le ciment déchromé qui ne dépasse pas les $5 \%$, tout au long de l'expérimentation, dans les microcosmes $\mathrm{E}$ et une toxicité relativement aiguë du ciment non déchromé (elle passe de $10 \%$, après $24 \mathrm{~h}$ d'expérimentation, à $35 \%$, après $48 \mathrm{~h}$ d'expérimentation). Cette figure montre aussi une toxicité aiguë des deux types de ciment en présence de sédiment (microcosmes ES); la mortalité atteint les $85 \%$ dans les aquariums contaminés par le ciment déchromé et $67,5 \%$ dans les aquariums contaminés par le ciment non déchromé, après seulement $48 \mathrm{~h}$ d'expérimentation et les $100 \%$ dans les deux types de contaminants après $72 \mathrm{~h}$ d'expérimentation. Cela nous conduit à supposer que le ciment pourrait contenir d'autres éléments toxiques, amenés à se déposer et à s'accumuler dans le sédiment, dont l'association aurait un effet plus toxique que la seule présence du chrome hexavalent. On met donc ainsi en évidence d'autres effets toxiques que ceux du chrome lui-même. Il s'agit entre autres d'éléments tels que du cuivre, du nickel, $\mathrm{du}$ plomb, du vanadium ou encore du zinc (MOUDILOU, 2000). D'ailleurs, ces cinq éléments font partie des dix métaux considérés comme les plus préoccupants pour l'environnement et les plus toxiques pour les écosystèmes aquatiques (ISLAM et TANAKA, 2004). Ces dix métaux sont, par ordre décroissant de toxicité : mercure, cadmium, argent, nickel, sélénium, plomb, cuivre, chrome, arsenic et zinc. Le cuivre et le zinc, par exemple, sont indispensables au métabolisme des êtres vivants, en participant au déroulement de nombreux processus biologiques. Ils peuvent aussi devenir particulièrement toxiques lorsque leur concentration dans l'environnement dépasse un certain seuil (ROESIJADI, 1992). Le zinc ne constitue pas un des contaminants les plus dangereux, bien qu'il entraîne, à des concentrations élevées, un certain nombre de disfonctionnements notamment au niveau de la croissance et de la reproduction (PAUL-PONT, 2010).

Cette différence qui ne peut pas être attribuée au chrome lui-même présent dans l'eau provient probablement d'autres substances toxiques apportées par le ciment ou peut-être aussi d'une fixation du chrome par les palourdes plus importante là où elles absorbent des particules fines en suspension, provenant par exemple du ciment même filtré au départ (particules pouvant avoir adsorbé du chrome à leur surface), mais particules évidemment absentes dans l'aquarium pollué au dichromate.

La toxicité de nombreux ions métalliques (ou semimétalliques comme l'arsenic) ne fait pas de doute, chez l'animal comme chez l'Homme. Cependant, son évaluation précise et la fixation de normes indiquant des valeurs seuil à ne pas dépasser dans les milieux aquatiques (pour la conservation de la biodiversité), ou dans l'eau potable (pour protéger la santé de l'Homme), sont encore bien empiriques et mériteraient certainement d'être précisées. Par exemple un certain nombre de métaux tels que le plomb, le nickel ou le cuivre sont depuis longtemps, entre autres, considérés comme potentiellement toxiques et leur concentration maximale acceptable dans l'eau 


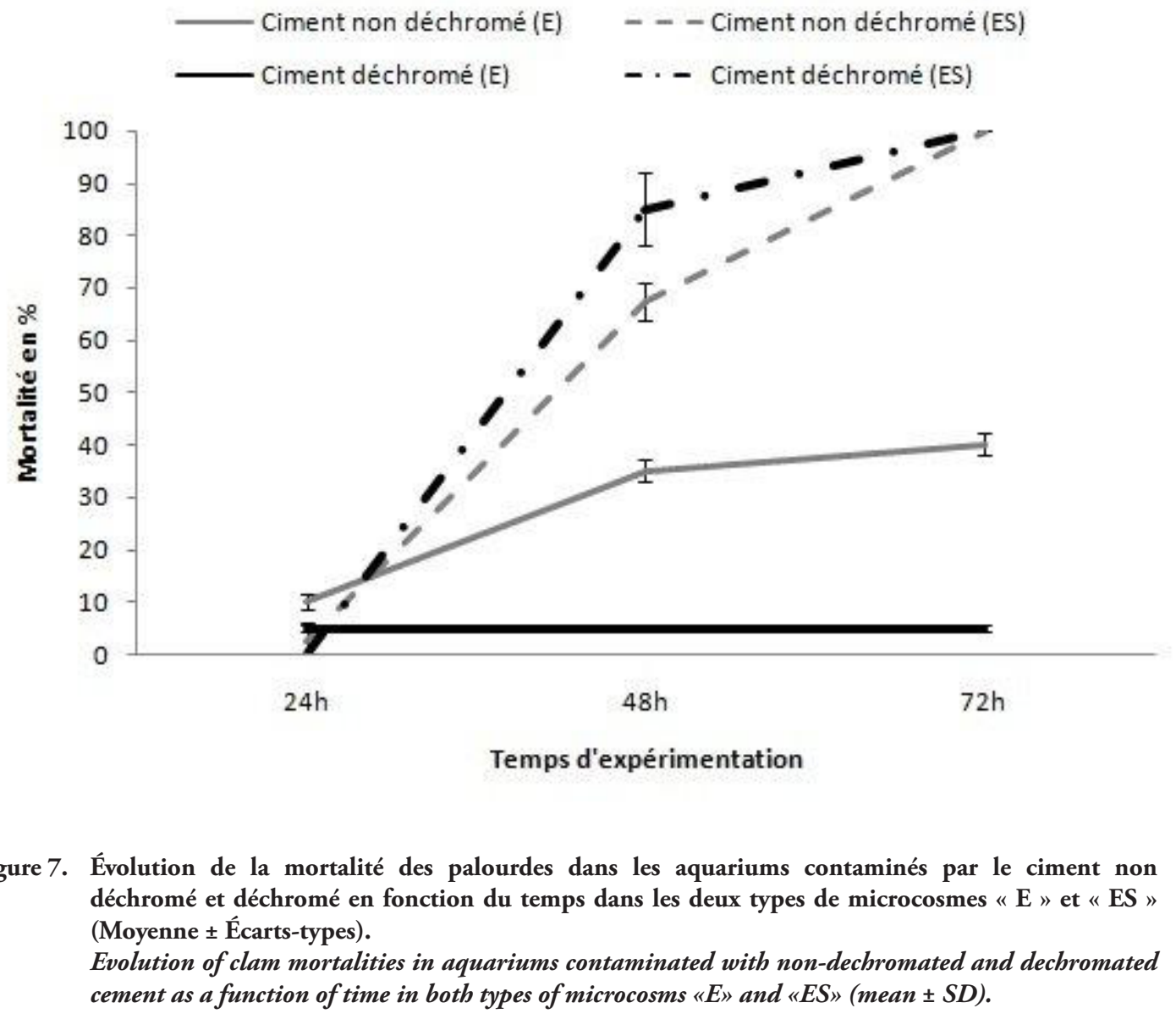

serait de $50 \mu \mathrm{g} \bullet \mathrm{L}^{-1}$ selon les normes françaises et européennes, mais cette valeur vient d'être ramenée pour le plomb à $25 \mu \mathrm{g} \bullet \mathrm{L}^{-1}$ dans les normes européennes, et il a été décidé qu’elle serait fixée à $10 \mu \mathrm{g}^{\bullet} \mathrm{L}^{-1}$, donc encore abaissée, dès 2013 . Le seuil considéré comme " tolérable " à défaut d'être « acceptable " est donc divisé par 2 puis finalement par 5. Ce n'est qu'un exemple qui montre la fragilité de nos évaluations de la toxicité relative de ces différents métaux, évaluations qui risquent souvent d'être revues à la baisse.

Il se trouve que très souvent la toxicité des divers éléments a été évaluée en les considérants seuls, alors que les effets toxiques (aigus ou chroniques) d'un élément peuvent apparaître à des teneurs très inférieures à celles qui ont été " déterminées ", en cas de " cocktails " réunissant une série de polluants différents qui agissent simultanément. Il peut arriver en effet que les effets de différents métaux fassent plus que s'additionner mais se potentialisant en cas de mélange, même lorsque certains des toxiques sont présents à des concentrations très inférieures à leur seuils reconnus de toxicité. Il est très possible qu'un tel phénomène de potentialisation contribue à expliquer qu'une concentration de chrome (VI) de $0,05 \mathrm{mg} \bullet \mathrm{L}^{-1}$ provenant d'une suspension de ciment "déchromé " entraîne une mortalité bien plus importante qu'une concentration de $0,16 \mathrm{mg}^{\bullet} \mathrm{L}^{-1}$ due à une solution de dichromate de potassium dans les aquariums ES (Figure 6), même si les observations visualisées sur cette figure 6 peuvent plus simplement révéler la présence de toxiques autres que le chrome dans le ciment.

Il résulte donc du présent travail que pour savoir de façon plus précise ce qu'il en est, il sera nécessaire de procéder au laboratoire à de nouvelles expérimentations, sur différents modèles animaux placés en élevage dans une série de situations différentes, et bien sûr prendre en compte aussi la composition chimique précise des ciments testés.

\subsection{Réponse des bactéries indigènes du sédiment}

La charge moyenne des bactéries indigènes a été maximale, atteignant 4,029 $\log (\mathrm{x}+1)$ bactéries par $\mathrm{mL}$ au niveau des microcosmes contenant du ciment déchromé, et minimale, atteignant 3,957 $(\log (\mathrm{x}+1)$ bactéries par $\mathrm{mL}$ au niveau de l'enceinte renfermant du ciment non déchromé (Figure 8).

Toutefois les différences observées entre la densité bactérienne moyenne des sédiments en présence de dichromate et celle des sédiments placés en présence de ciment " déchromé " ne sont pas significatives. La plus grande variabilité des valeurs estimées en présence de ciment pourrait provenir de petites différences de composition chimique des 


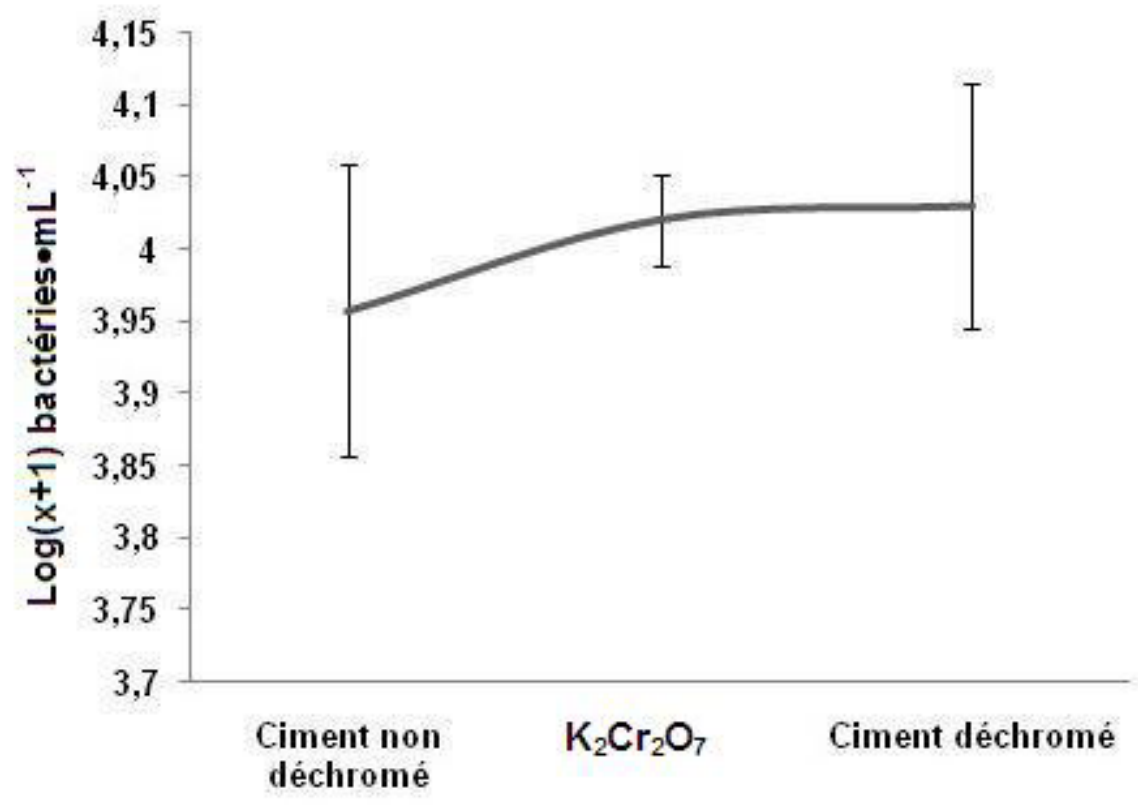

Figure 8. Dénombrement de la charge des bactéries indigènes totales du sédiment dans les différents tests après $72 \mathrm{~h}$ d'expérimentation $(\log (x+1))$ (Moyenne \pm Écarts-types).

Total counts of the indigenous bacteria in the sediment in the various tests after $72 b(\log (x+1))($ Mean $\pm S D)$.

différents échantillons de ciment déchromé utilisés, alors que la solution de dichromate et l'eau de mer utilisée est certainement sujette à de moindres variations. Ces possibles variations de la toxicité des échantillons de ciment - due à des quantités de composantes et pas seulement au chrome (VI) - expliqueraient également qu'en présence de ciment non déchromé, la densité bactérienne des sédiments varie presque autant qu'en présence de ciment déchromé.

De nombreux travaux ont montré que les sédiments lagunaires contiennent, outre les hydrocarbures et les antibiotiques, des métaux lourds issus des rejets industriels et urbains (BEN SAID et al., 2010b). L'apport continu de polluants a très certainement favorisé la sélection et l'adaptation des bactéries à ces produits délétères et leur a permis, dans notre cas, d'acquérir une résistance à certains métaux tel le chrome, le métal étudié, ce qui explique la charge élevée en bactéries (BEN SAID et al., 2008).

Selon DESJARDIN (2002), la réduction microbienne du chrome (VI) peut être directe ou indirecte. Des souches bactériennes anaérobies isolées à partir de sols fortement chargés en chrome sont capables de le réduire. L'existence de bactéries capables de réduire le chrome en présence d'oxygène permet d'envisager la bio-réduction comme un mécanisme de résistance au chrome. La réduction directe mettrait en jeu une enzyme dont le gène serait porté par un plasmide et la vitesse de cette réaction serait en relation avec la disponibilité en source de carbone (DESJARDIN, 2002).
D'autant qu'en plus d'un mécanisme enzymatique de réduction du chrome déjà connu chez plusieurs bactéries, il est fait allusion dans l'article de DESJARDIN et al. (2003) à un catalyseur de réduction non enzymatique qui, libéré dans le milieu, peut agir hors de la cellule bactérienne et laisser entrevoir des perspectives d'utilisation pour abaisser la teneur en chrome (VI) d'un sol ou d'un milieu aquatique pollué.

\section{CONCLUSION}

La teneur en chrome (VI) diminue considérablement dans un microcosme contenant de l'eau de mer et du sédiment, et ne varie pas dans une enceinte renfermant uniquement de l'eau de mer, ce qui montre que certains éléments du sédiment favorisent la réduction du chrome (VI) en chrome (III), en l'occurrence le fer et la matière organique. Dans la mesure où seul le chrome (VI) dans l'eau a été dosé, il conviendra cependant de s'assurer, lors d'expérimentations ultérieures, que cet abaissement de la concentration de l'eau en chrome (VI) n'est due non pas à une réduction mais à un simple phénomène d'adsorption (non biologique) des bactéries sur des particules du sédiment en réalisant des essais avec un sédiment préalablement stérilisé.

Le chrome (VI) n'est pas le seul élément toxique présent dans le ciment. Ceci a été démontré dans la présente étude 
par le pourcentage de mortalité des palourdes (100\% dans les microcosmes eau-sédiment contaminés par le ciment contre $40 \%$ dans le même type de microcosme contaminé par le dichromate de potassium). Nos résultats confirment l'intérêt des palourdes comme modèle d'animal microphage, utilisable pour la bio-surveillance de l'environnement marin, et leur rôle de bioindicateurs de pollution. Cependant, le déchromage atténue mais n'évite pas l'effet toxique du ciment, et ceci nous incite à étudier en détail la composition des deux types de ciment pour mettre en évidence la cause de cette toxicité observée, mais toujours étant que le ciment déchromé reste une première solution à envisager pour la problématique du ciment.

Le fait que la mortalité des palourdes ait été plus élevée dans les microcosmes eau-sédiment que dans ceux contenant de l'eau de mer seulement nous incite à envisager l'estimation des teneurs en chrome dans le sédiment et dans la chair afin d'évaluer le devenir du métal dans les différents compartiments de l'écosystème. Enfin, la présence possible d'autres substances toxiques dans le sédiment devra être envisagée et recherchée (par exemple en utilisant un microcosme témoin contenant un sédiment artificiel de composition connue et sans aucun polluant, métallique ou autre).

\section{REMERCIEMENTS}

Nous exprimons nos plus vifs remerciements à la société "Les Ciments de Bizerte " pour son soutien financier ainsi qu'aux membres de son laboratoire «Contrôle qualité ».

\section{RÉFÉRENCES BIBLIOGRAPHIQUES}

AFRI-MEHENNAOUI F.Z., L. SALHI, N. ZERIEF et S. MEHENNAOUI (2009). Niveau de contamination par les éléments traces métalliques (ETM), des sédiments des oueds Rhumel et Sakiet Roum, dans la zone industrielle et à Constantine (Algérie). Dans : Colloque International Environnement et Transports Dans Des Contextes Différents, Actes. 16-18 février, Ghardaïa, Algérie, ENP (Éditeur), pp. 181-187.

ALLOWAY B.J. (1995). Soil processes and the behavior of heavy metals. Dans : Heavy Metals in Soil, ALLOWAY, B.J. (Éditeur), Springer-Verlag, 2e édition, Berlin, 368 p.

AMIARD J.C., C. METAYER, J.P. BAUD et F. RIBEYRE (1991). Influence de divers facteurs écologiques sur la bioaccumulation d'éléments métalliques $(\mathrm{Cd}, \mathrm{Cu}, \mathrm{Pb}$,
Zn) chez de jeunes palourdes (Ruditapes philippinarum) au cours du prégrossissement en nourricerie. Rev. Sci. Eau, 4, 441-452.

BARRO A. (2010). L'urbanisation non maitrisée et le risque industriel: cas de la centrale électrique de Kounoune. Mémoire, École Nationale d'Économie Appliquée (ENEA), Dakar, Sénégal, $97 \mathrm{p}$.

BARTLETT R.J. et J.M. KIMBLE (1976). Behavior of chromium in soils: II. Hexavalent forms. J. Environ. Qual., 5, 383-386.

BEN SAID O., M. GOÑI-URRIZA, M. EL BOUR, M. DELlALI, P. AISSA et R. DURAN (2008). Characterization of aerobic polyaromatic hydrocarbondegrading bacteria from Bizerte lagoon sediments, Tunisia. J. Appl. Microbiol., 104, 987-997.

BEN SAID O., M. GONII-URRIZA, M. EL BOUR, P. AISSA et R. DURAN (2010a). Bacterial community structure of sediments of the Bizerte lagoon (Tunisia), a Southern Mediterranean coastal anthropized lagoon. Microb. Ecol., 59, 445-456.

BEN SAID O., M. GOÑI-URRIZA, M. EL BOUR, R. DURAN et P. AISSA (2010b). Diversité des bactéries capables de dégrader les hydrocarbures aromatiques polycycliques et résistantes aux métaux et aux antibiotiques isolées à partir des sédiments de la lagune de Bizerte, Tunisie. Rev. Microbiol. Ind. San. Environ., 4, 32-48.

BUERGE I.J. et S.L. HUG (1997). Kinetics and pH dependence of chromium (VI) reduction by iron (II). Environ. Sci. Technol., 31, 1426-1432.

CEAEQ (2008). Détermination du chrome hexavalent : méthode colorimétrique. Centre d'expertise en analyse environnementale au Québec. http://www.ceaeq.gouv. qc.ca/methodes/pdf/MA200CrHex11.pdf, (consultaté en mai 2010).

CHIFFOLEAU J.C. (2001). La contamination métallique, IFREMER, Région Haute Normandie. (Programme scientifique Seine-Aval), 8, 39 p.

CHOUBA L., Ch. TISSAOUI et EL A. ABED (2008). Étude de la concentration des métaux traces chez Hexaplex trunculus (muricidae) le long du littoral tunisien. Bull. INSTM (Institut National des Sciences et Technologies de la Mer, Tunisie), 35, 73-79.

COMMISSION EUROPÉENNE (2003). "Directive 2003/53/EC of the European Parliament amending the $26^{\text {th }}$ 
time Council Directive 76/769/EEC relating to restrictions on the marketing and use of certain dangerous substances and preparations (nonylphenol, nony; phenol ethoxylate and cement)".

COMMISSION EUROPÉENNE (2010). Industries $d u$ ciment, de la chaux et de la magnésie. http://www.ineris. $\mathrm{fr} /$ ippc/sites/default/files/files/clm_bref_0510_VF_1.pdf (consultation le 25 avril 2011).

CUQ J.L. (2008). Microbiologie alimentaire, contrôle microbiologique des aliments. Manuel technique, Polytech., Département STIA, Université Montpellier 2, Sciences et Techniques, 119 p. http://mon.univ-montp2.fr/claroline/ backends/download.php?url=L0FuYWx5c2VzX7ViaW9 sb2dpcXVlcy5wZGY\%3D\&cidReset=true\&cidReq=CO MICRO (consultation septembre 2011).

DELLALI M., M. ROMÉO et P. AISSA (2001). Suivi annuel de l'activité catalase chez des moules et des palourdes originaires de la lagune de Bizerte. Oceanol. Acta, 24, 263-271.

DESJARDIN V. (2002). Réduction du chrome (VI) par la souche Streptomyces thermocarboxydus NH50 isolée à partir d'un sol pollué. Thèse de doctorat, Institut national des sciences appliquées de Lyon, France, 236 p.

DESJARDIN V., R. BAYARD, Ph. LEJEUNE et $R$. GOURDON (2003). Utilisation of supernatants of pure cultures of Streptomyces thermocarboxydus NH50 to reduce chromium toxicity and mobility in contaminated soils. Water Air Soil Pollut.: Focus, 3, 153-160.

FENDORF S.E. (1995). Surface reactions of chromium in soils and waters. Geoderma, 67, 55-71.

GUILLON E. (2004). Durabilité des matériaux cimentaires - Modélisation de l'influence des équilibres physicochimiques sur la microstructure et les propriétés mécaniques résiduelles. Thèse de doctorat, École normale supérieure de Cachan, France, 154 p.

HEIKE S., S. MEINHARD et B. THORSTEN (2009). Cultivable bacteria from bulk water, aggregates, and surface sediments of a tidal flat ecosystem. Ocean Dynam., 59, 291-304.

INERIS (2005). Fiche de données toxicologiques et environnementales des substances chimiques: CHROME ET SES DÉRIVÉS. DRC-01-05590-00DF253.doc, Version $\mathrm{N}^{\circ} 2: 80 \mathrm{p}$.
ISLAM M.D. et M. TANAKA (2004). Impact of pollution on coastal and marine ecosystems including coastal and marine fisheries and approach for management: a review and synthesis. Mar. Pollut. Bull., 48, 624-649.

JAMES B.R. et R.J. BARTLETT (1983). Behavior of chromium in soils: VII. Hexavalent forms. J. Environ. Qual., 12, 177-181.

JOUANY J.M., P. VASSEUR et J.F. FERARD (1982). Écotoxicité directe et intégrée du chrome hexavalent sur deux niveaux trophiques associés : Chlorella vulgaris et Daphnia magna. Environ. Pollut. (Series A), 27, 207-221.

LOOTENS D. (2004). Ciments et suspensions concentrées modèles. Écoulement, encombrement et floculation. Thèse de Doctorat, Univ. Pierre et Marie Curie, France, 172 p.

LOUATI H., O. BEN SAID, A. SOLTANI, E. MAHMOUDI, C. CRAVO-LAUREAU, R. DURAN, O. PRINGAULT et P. AISSA (2012). Microbial community responses to bioremediation treatments for the mitigation of low-dose anthracene in marine coastal sediments of Bizerte lagoon (Tunisia). Environ. Sci. Pollut. Res. DOI: 10.1007/s11356012-0860.

CEAEQ (2008). Détermination du chrome hexavalent : méthode colorimétrique. Centre d'expertise en analyse environnementale au Québec. http://www.ceaeq.gouv. qc.ca/methodes/pdf/MA200CrHex11.pdf, (consultation mai 2010).

MAKDISI R.S. (1992). Tannery wastes definition, risk assessment and cleanup options, Berkeley, California. J. Hazard. Mater., 29, 79-96.

MOUDILOU E. (2000). Cinétiques et mécanismes de relargage des métaux lourds présents en traces dans les matrices cimentaires. Thèse de Doctorat, École Supérieure de l'Énergie et des Matériaux, Orléans, France, 219 p.

NF EN 196-10 : Norme Européenne - Norme Française 196-10 (2009). Méthodes d'essais des ciments. Partie 10 : Détermination de la teneur du ciment en chrome (VI) soluble dans l'eau.

OMS/PNUE (1995). Recommandations pour la surveillance sanitaire des zones côtières à usage récréatif et des zones conchylicoles (Parties II et III). Programme à long terme de surveillance continue et de recherche en matière de pollution de la mer Méditerranée. (MED/POL phase II et III), Danemark, 75 p. 
OPPBTP : Organisme Professionnel de Prévention du Bâtiment et des Travaux Publics, France (1990). Fiche de sécurité H2 F 1499.

PALMER C.D. et P.R. WITTBRODT (1991). Processes affecting the remediation of chromium-contaminated sites. Environ. Health Perspect., 92, 25-40.

PAUL-PONT I. (2010). Sensibilité et adaptation de populations de bivalves marins soumis à des stress multiples: infestation parasitaire, contamination microbienne et pollution métallique. Thèse de Doctorat, Univer. Bordeaux 1, France, 339 p.

PETTINE M., L. D’OTTONE, L. CAMPANELLA, F.J. MILLERO et R. PASSINO (1998). The reduction of chromium by iron (II) in aqueous solutions. Geochim. Cosmochim. Acta, 62, 1509-1519.

ROESIJADI G. (1992). Metallothioneins in metal regulation and toxicity in aquatic animals. Aquat. Toxicol., 22, 81-114.

SEDLAK D.L. et P.G. CHAN (1997). Reduction of hexavalent chromium by ferrous iron. Geochim. Cosmochim. Acta, 61, 2185-2192.

TRIFFAULT-BOUCHET G. et L. MARTEL (2005). Évaluation écotoxicologique d'une solution de précipitation/ recouvrement en vue de réduire l'eutrophisation dans les lacs canadiens. http://www.gci.ulaval.ca/professeurs/rgalvez/ projets_fichiers/MDDEP/MDDEP-GTB.pdf. (consulté en Juillet 2011). 